Apollonia, but some of the ancient English people looked upon Saint Lucia as the luminary responsible for both sets of organs. Let me conclude with the hope that this primitive belief was of good augury, and that it will serve to emphasise the significance of our eye-teeth.

\title{
LITERATURE
}

BEnEDICT, W. L. (1941).-Hyperostosis of the orbit. Amer. J. Ophthal., 24, 1005.

Clifton, W. M., Frank, A. A. and FreEman, S. (1938).--Osteopetrosis (Marble bones). Amer. J. Dis. Child., 56, 1020.

Dessoff, J. (1934).-Blue sclerotics, fragile bones and deafness. Arch. of Ophthal., 12, 60 .

FREY, W. G. (1937).-Paget's disease of the skull. Ibid., 18, 477.

GuYton, J. B. and Woods, A. C. (1941).-Etiology of uveitis. Ibid., 26, 983.

KRAVITZ, D. (1946).- Infections and reflex disorders of the eye from dental infection. Amer. J. Ophthal., 29, 1135.

ROPER-HALL, H. T. (1.942). - Oral sepsis in relation to ophthalmology. Brit. J. Ophthal., 26, 141.

Rushton, M. A. (1948).-Advances in the treatment of oral and dental diseases. Pract., 161, 321.

SJöGREN, H. (1948).-Kerato-conjunctivitis sicca and chronic polyarthritis. Acta Med. Scand., 130, 484.

Souter, W. C. (1930).-Disorders of secretion of endocrine glands. Trans. Ophthal. Soc. U.K., 50, 69.

Wheeler, J. M. (1934).-Schüller-Christian-Hand disease (Xanthomatosis).Arch. of Ophthal., 11, 214.

WILMER, W. H. (193:). The relation of teeth to diseases of the eye. Arch. of Ophthai., 4,.453.

$\because$

\section{CONCENTRATION IN THE AQUEOUS OF VARIOUS SULPHONAMIDES AFTER SYSTEMIC ADMINISTRATION*}

\author{
BY \\ ARNOLD SORSBY
}

LONDON

ThE earlier experimental studies of Bellows and Chinn (1939 and 1941), Pinkoff (1939), Meyer, Bloch and Chamberlain (1941), Liebman and Newman (1941), and Scheie and Souders (1941), have established that sulphanilamide and sulphapyridine penetrate readily into the interior of the eye on oral administration, whilst sulphathiazole has a poor penetration: The penetration of sulphadiazine was found to be high (Scheie and Souders, 1941; Liebman and Newman, 1941). There do not appear to be any studies on the newer sulphonamides such as sulphamezathine and sulphamerazine. For clinical purposes sulphanilamide and sulphapyridine can be ignored as they are no longer widely used owing to their relative toxicity. In practice the choice to-day is

* Dedicated to Professor J. Meller. 
largely limited to sulphadiazine, sulphamerazine, sulphamezathine and sulphathiazole. The present study was undertaken to assess the relative penetration of these sulphonamides into the aqueous.

Animals used. The penetration of sulphadiazine, sulphamerazine and sulphamezathine into the aqueous was determined in rabbits. The penetration of these sulphonamides, as also of sulphanilamide and sulphathiazole, was studied in the rat.

Technique. In the rabbit a dose of $100 \mathrm{mg}$. per kg. of bodyweight of sulphadiazine, sulphamerazine and sulphamezathine was given intravenously, and the concentration of these different sulphonamides was assessed in the plasma, blood, and aqueous. In the rat a dose of $150 \mathrm{mg}$. per $\mathrm{kg}$. was given orally. The values recorded are in each case averages of readings in four animals for each time period shown.

Concentration in the Aqueous of the Rat

Figs. 1-5 show the concentrations obtained in the plasma, blood and primary aqueous from the administration of each of the five sulphonamides studied, sulphanilamide, sulphadiazine,

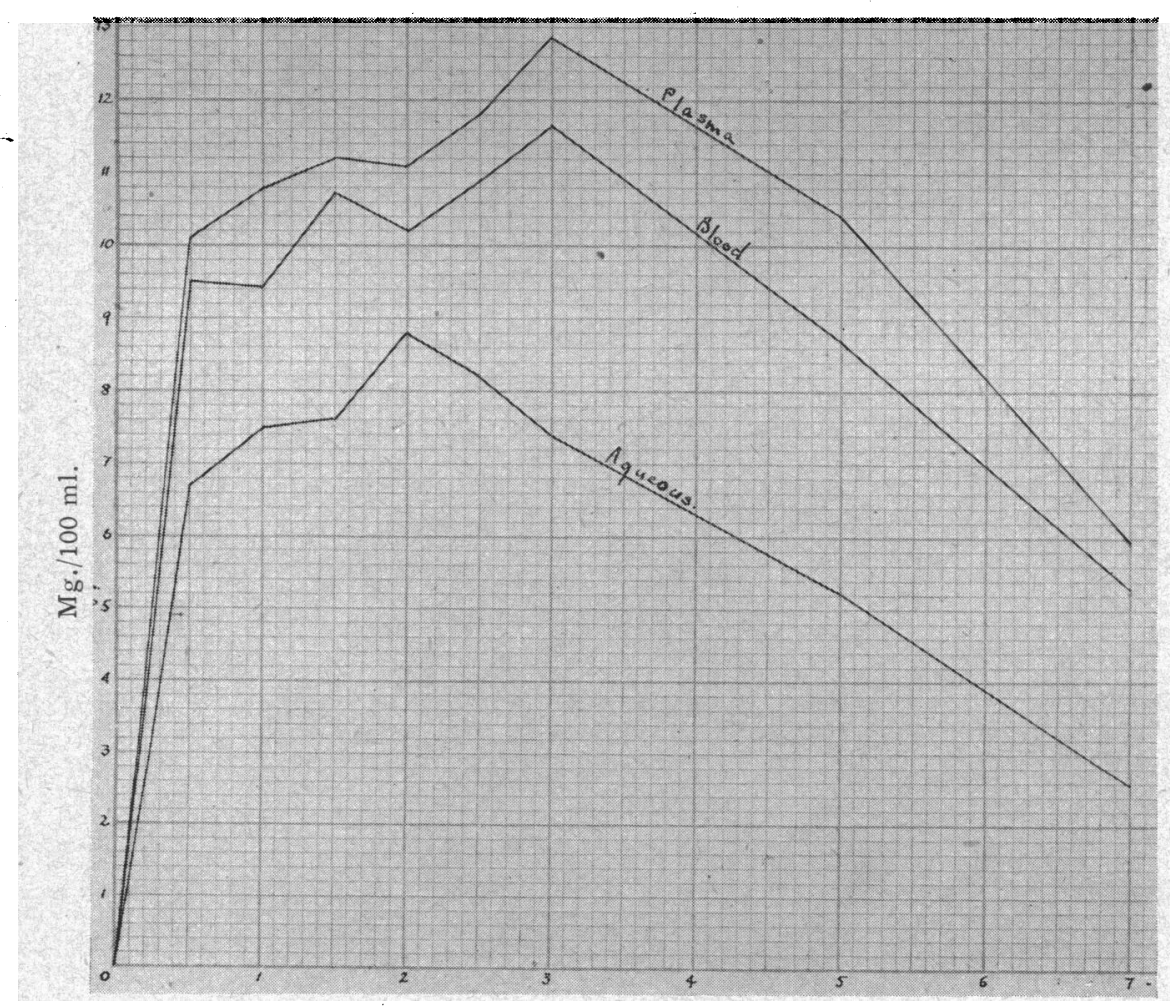

FIG. 1. - Sulphanilamide $-150 \mathrm{mg} / \mathrm{kg}$. orally in rats. 
sulphamerazine, sulphamezathine and sulphathiazole. Fig. 1 confirms earlier observations that with sulphanilamide high immediate levels are obtained in plasma, blood and aqueous. It will be seen that at 7 hours the aqueous level is still as high as $2.6 \mathrm{mg} . / 100 \mathrm{ml}$. Fig. 2 shows that sulphadiazine has a rather lower level, whilst Fig. 3 shows a somewhat higher level with

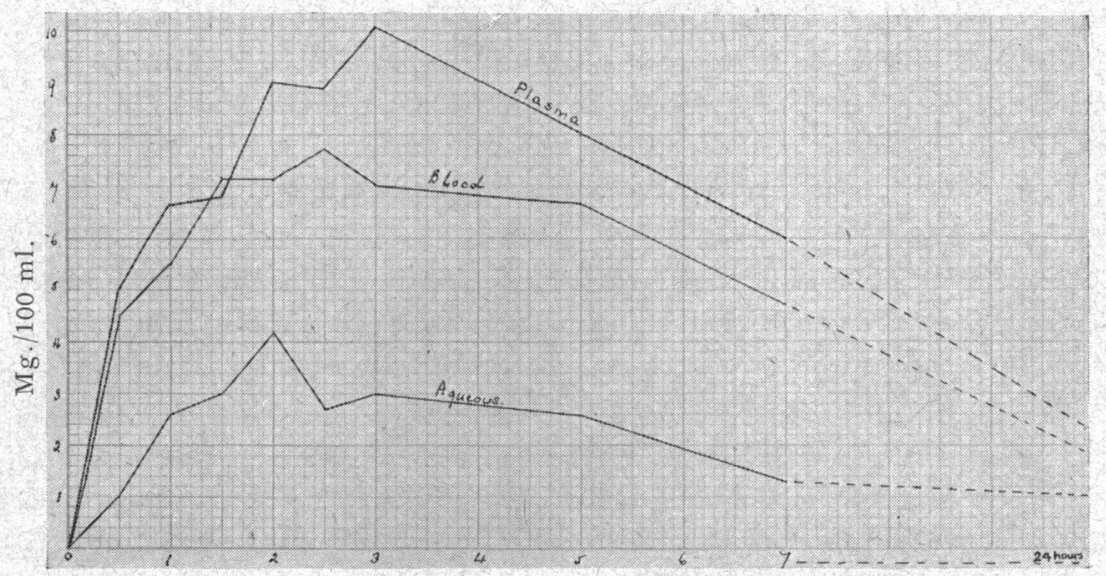

FIG. 2.-Sulphadiazine $-150 \mathrm{mg} . / \mathrm{kg}$. orally in rats.

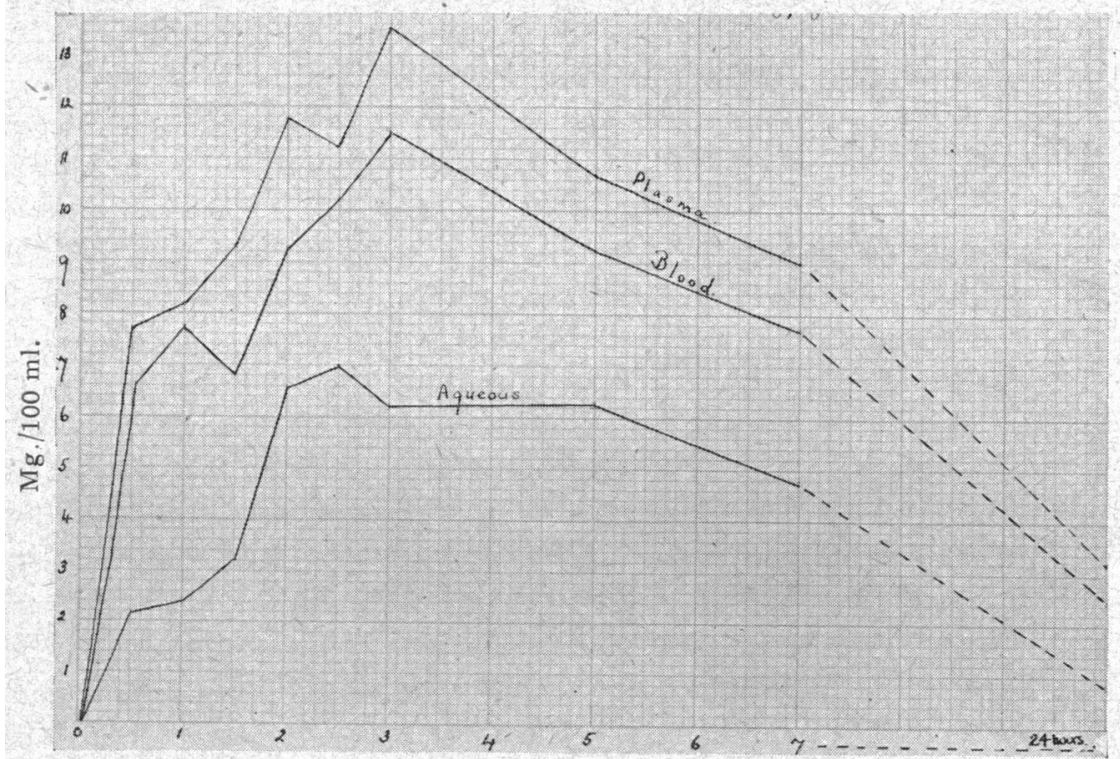

FIG. 3.-Sulphamerazine $150 \mathrm{mg} . / \mathrm{kg}$. orally in rats. 
sulphamerazine. The levels for sulphamezathine (Fig. 4) are lower than for sulphamerazine and not dissimilar to those for sulphadiazine. Fig. 5 shows a consistently low level for sulphathiazole, with total disappearance of any concentration by

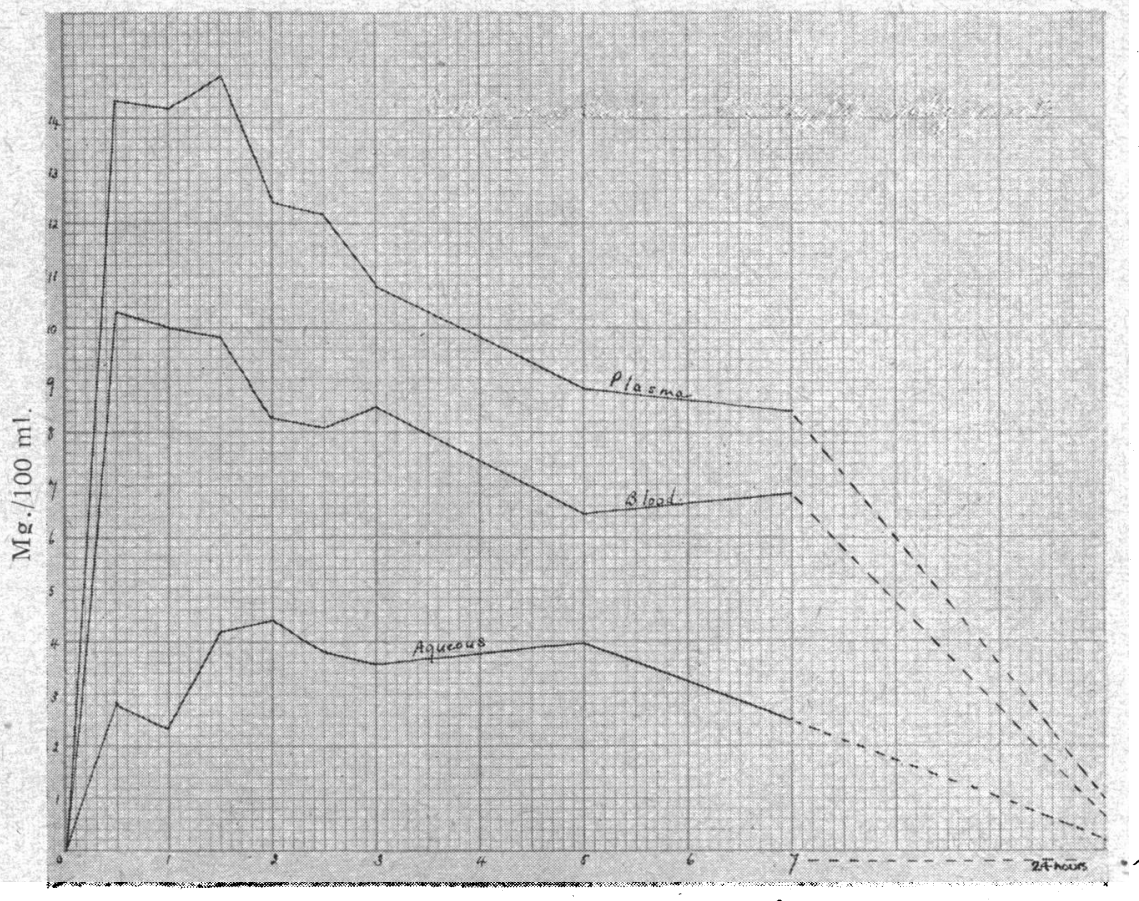

Fig. 4.-Sulphamezathine $-150 \mathrm{mg} . / \mathrm{kg}$. orally in rats.

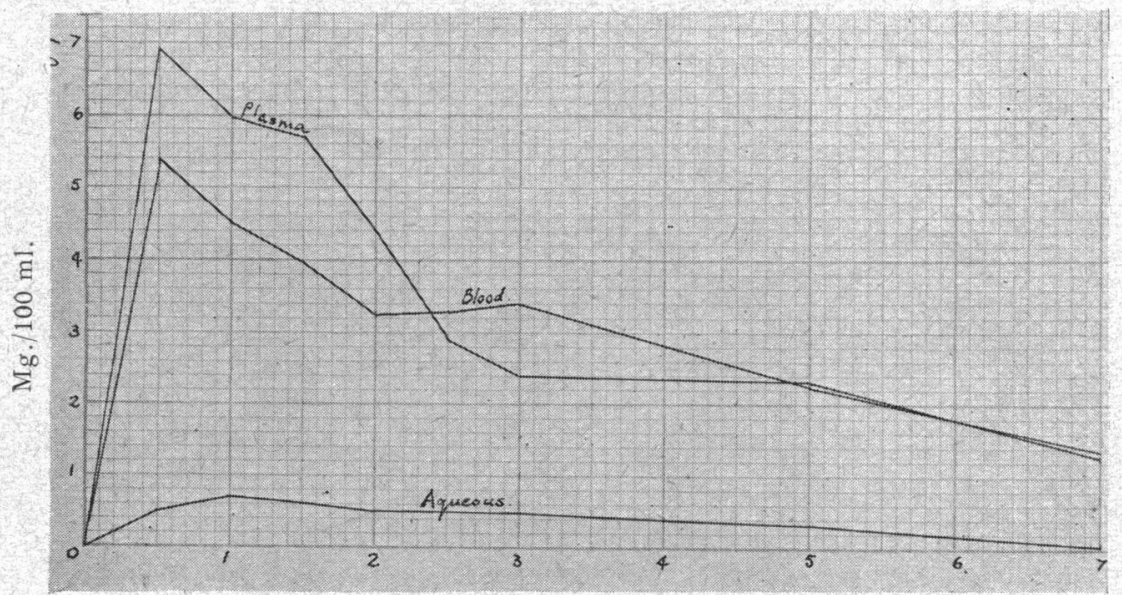

FıG. 5.-Sulphathiazole-15.0 mg./kg. in rats. 


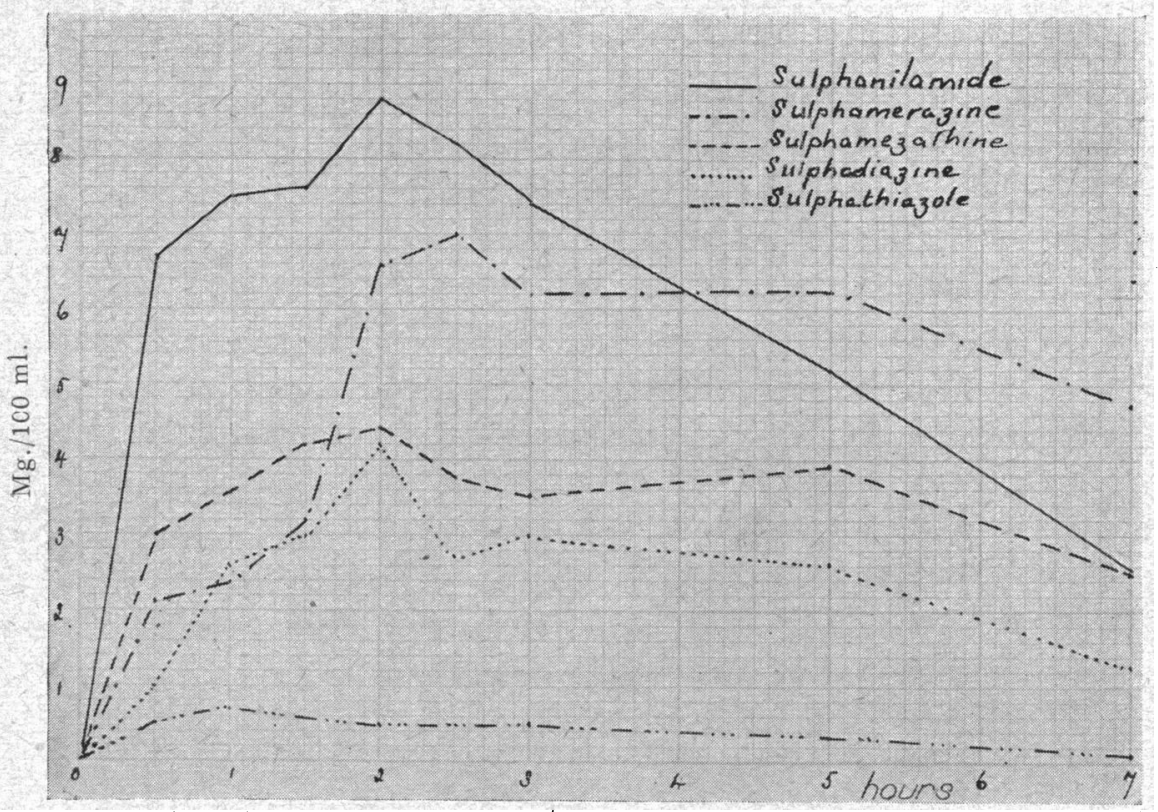

FIG. A.-Sulphonamides $-150 \mathrm{mg} . / \mathrm{kg}$. orally in rats. Comparison of the aqueous concentration.

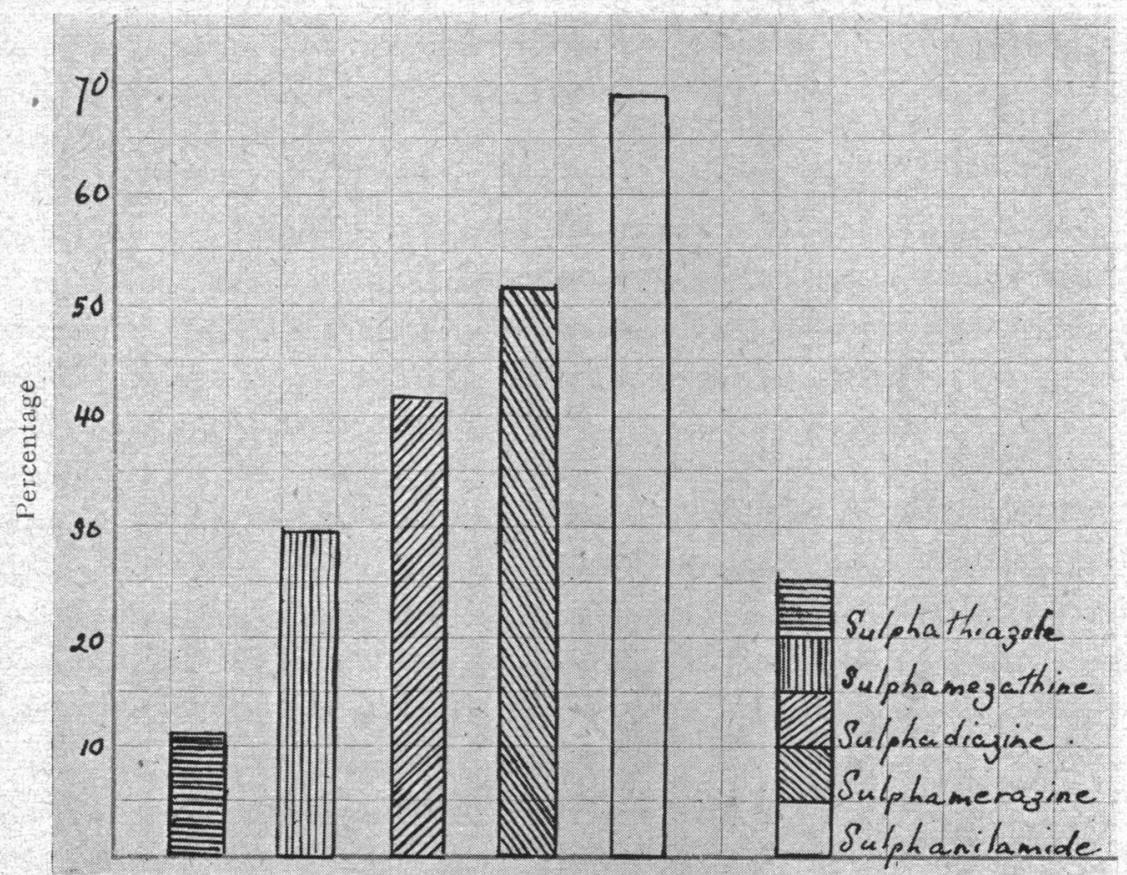

FIG. B.-Sulphonamides $-150 \mathrm{mg} . / \mathrm{kg}$. in rats.

Highest aqueous concentration as percentage of highest plasma concentration for each of the five sulphonamides. 


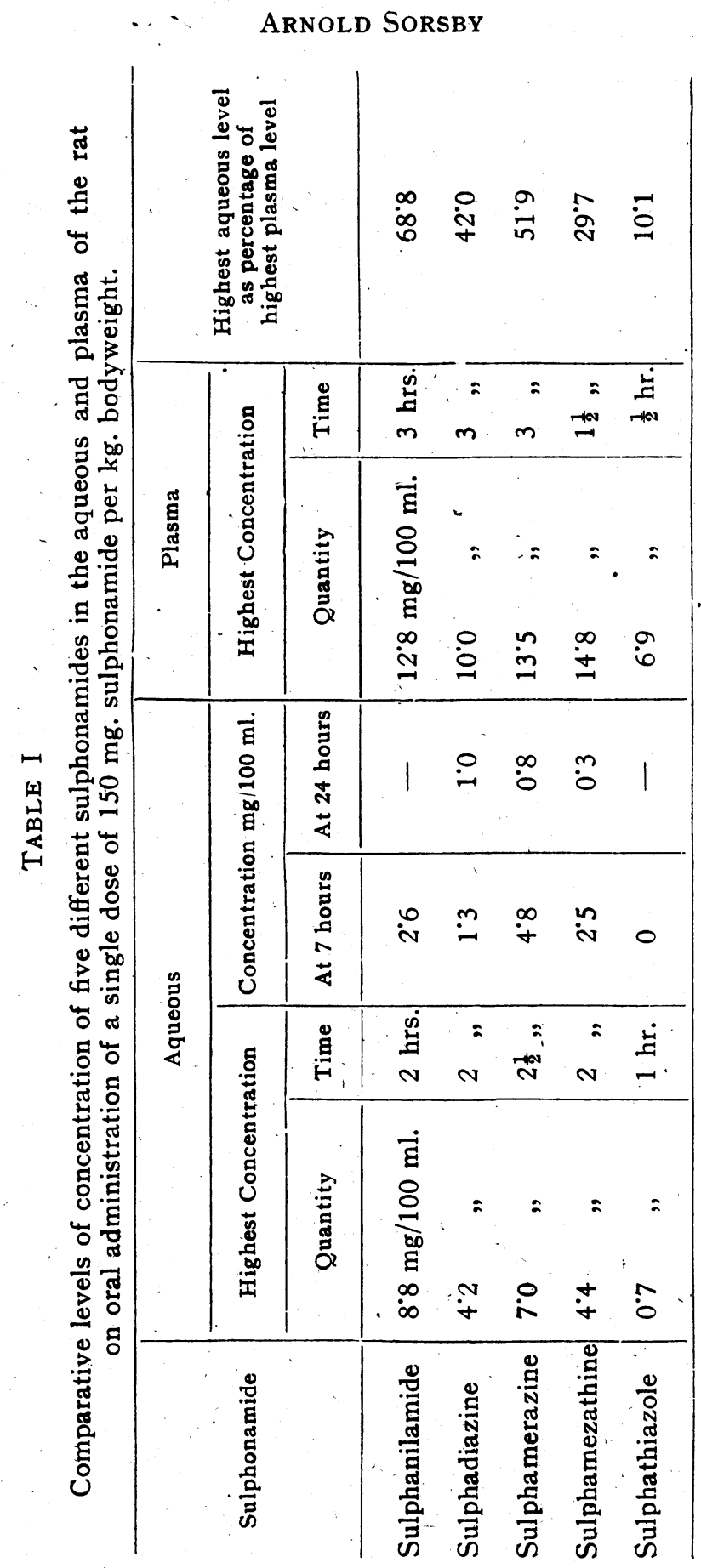


the 7th hour. At 24 hours there is no sulphanilanide at all in the aqueous, whilst the levels for sulphadiazine and sulphamerazine are around $1 \mathrm{mg}$. per $100 \mathrm{ml}$., with an even lower reading for sulphamezathine. The absolute aqueous concentrations of these five sulphonamides are contrasted in Fig. A, whilst Fig. B shows the highest aqueous levels as percentages of the highest plasma concentration of each of the five agents. The salient features brought out may be. summarised in the table.

It will be seen that on all counts sulphathiazole is the least satisfactory. Of the remaining four agents sulphanilamide and sulphamerazine both reach considerable aqueous levels, 8.8 and $7.0 \mathrm{mg} . / 100 \mathrm{ml}$. respectively at their peak, $\left(2\right.$ hours and $2 \frac{1}{2}$ hours respectively), as against 4.2 and $4.4 \mathrm{mg} . / 100 \mathrm{ml}$. respectively, (both at 2 hours) for sulphadiazine and sulphamezathine. At 7 hours sulphamerazine still has a relatively high level, $4.8 \mathrm{mg} . / 100 \mathrm{ml}$., whilst sulphamezathine has double the level of sulphadiazine, $2.6 \mathrm{mg} . / 100 \mathrm{ml}$. against 1.3 .

\section{Concentration in the Aqueous of the Rabit}

In the rabbit the plasma, blood and aqueous values for sulphadiazine, sulphamerazine and sulphamezathine after intravenous injection are shown in Figs. 6-8, and the aqueous values are contrasted in Fig. C. Fig. D shows the highest aqueous levels as percentages of the plasma levels at $\mathbf{3 0}$ minutes after injection.

The salient features are shown in the following summary table.

\section{TABLE II}

Comparative levels of concentration of three different sulphonamides in the aqueous and plasma of the rabbit on intravenous administration of $100 \mathrm{mg}$. sulphonamide per $\mathrm{kg}$. bodyweight.

\begin{tabular}{|c|c|c|c|c|c|}
\hline \multirow{3}{*}{ Sulphonamide } & \multicolumn{4}{|c|}{ Aqueous } & \multirow{3}{*}{$\begin{array}{l}\text { Highest aqueous level } \\
\text { as percentage of plasma } \\
\text { level at } \frac{1}{2} \text { hour }\end{array}$} \\
\hline & \multicolumn{2}{|c|}{$\begin{array}{c}\text { Highest } \\
\text { Concentration }\end{array}$} & \multicolumn{2}{|c|}{$\begin{array}{l}\text { Concentration } \\
\mathrm{mg} / 100 \mathrm{ml} .\end{array}$} & \\
\hline & Quantity & Time & At $3 \mathrm{hrs}$. & At $7 \mathrm{hrs}$. & \\
\hline Sulphadiazine & $6^{\circ} 0$ & $1 \frac{1}{2} \mathrm{hrs}$. & $1: 8$ & $0^{\circ} 2$ & $53^{\circ} 6$ \\
\hline Sulphamerazine & $3 \cdot 5$ & $\frac{1}{2} \mathrm{hr}$. & $1 \cdot 1$ & 0.2 & $52: 3$ \\
\hline Sulphamezathine & $5^{\circ} 0$ & $\frac{1}{2}$, & 0.6 & $0^{\circ} 0$ & $61^{\circ} 0$ \\
\hline
\end{tabular}




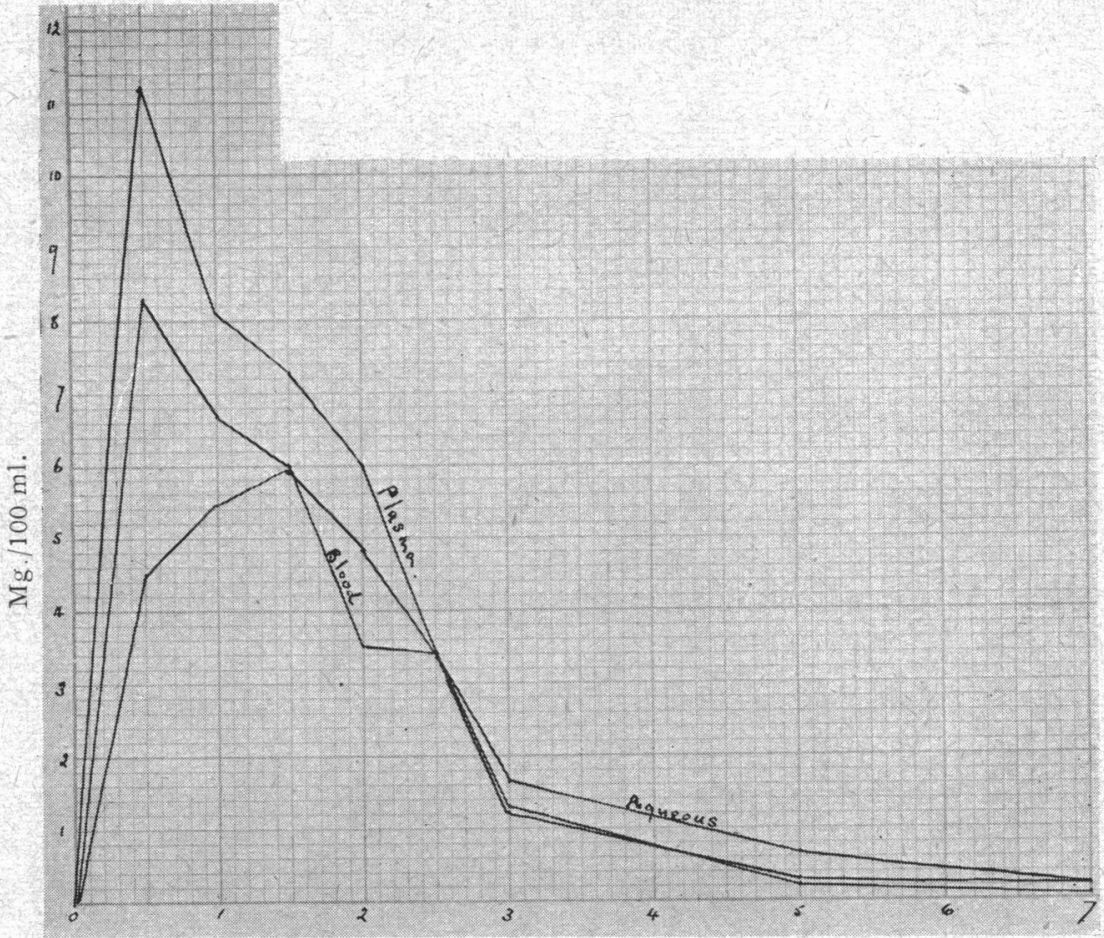

FIG. 6.-Sulphadiazine $-100 \mathrm{mg} . / \mathrm{kg}$. intravenously in rabbits.

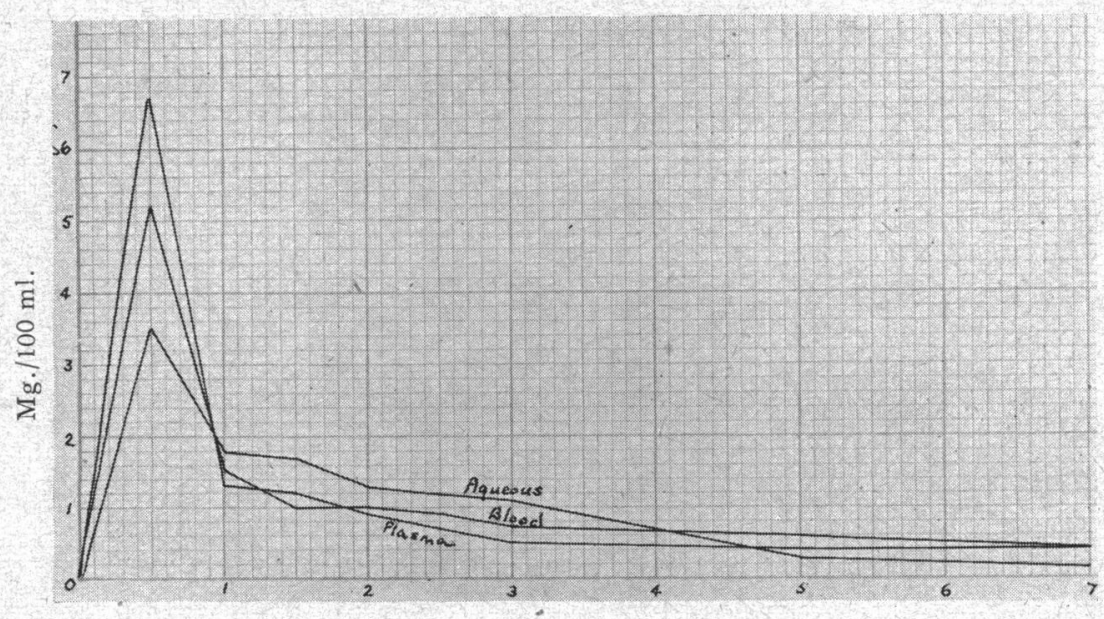

Fig. 7.-Sulphamerazine $100 \mathrm{mg} . / \mathrm{kg}$. intràv enously in rabbits. 
It is seen that the highest absolute aqueous concentration is reached with sulphadiazine, and that sulphamezathine gives a higher level than sulphamerazine. Sulphamezathine appears to be most rapidly eliminated, but it gives the highest ratio of aqueous/plasma concentration.

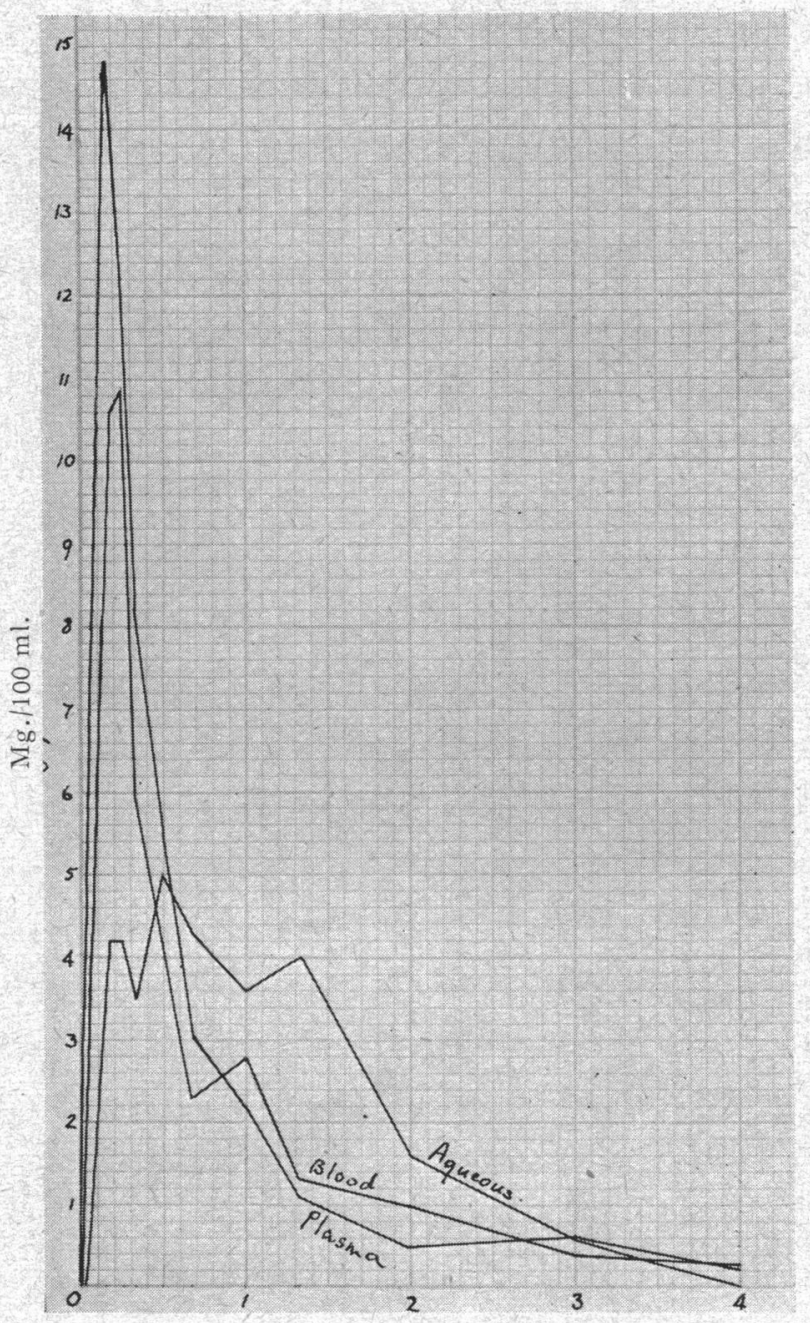

FIG: 8 - Sulphamezathine $100 \mathrm{mg} . / \mathrm{kg}$. intravenously in rabbits. 


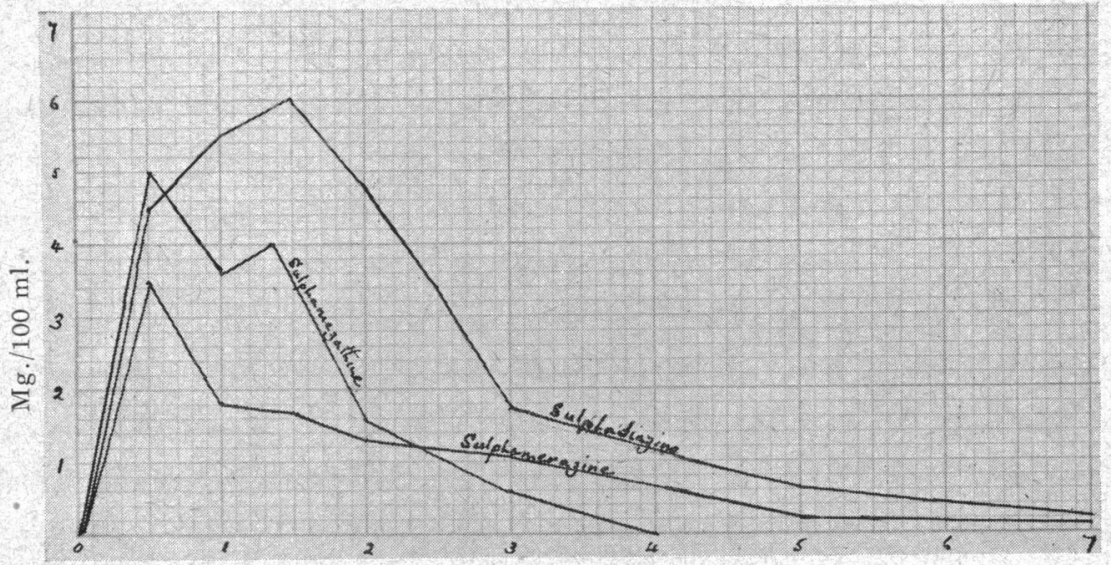

F1G. C. - Sulphonamides $-100 \mathrm{mg} . / \mathrm{kg}$. intravenously in rabbits. Comparison of the aqueous concentration.

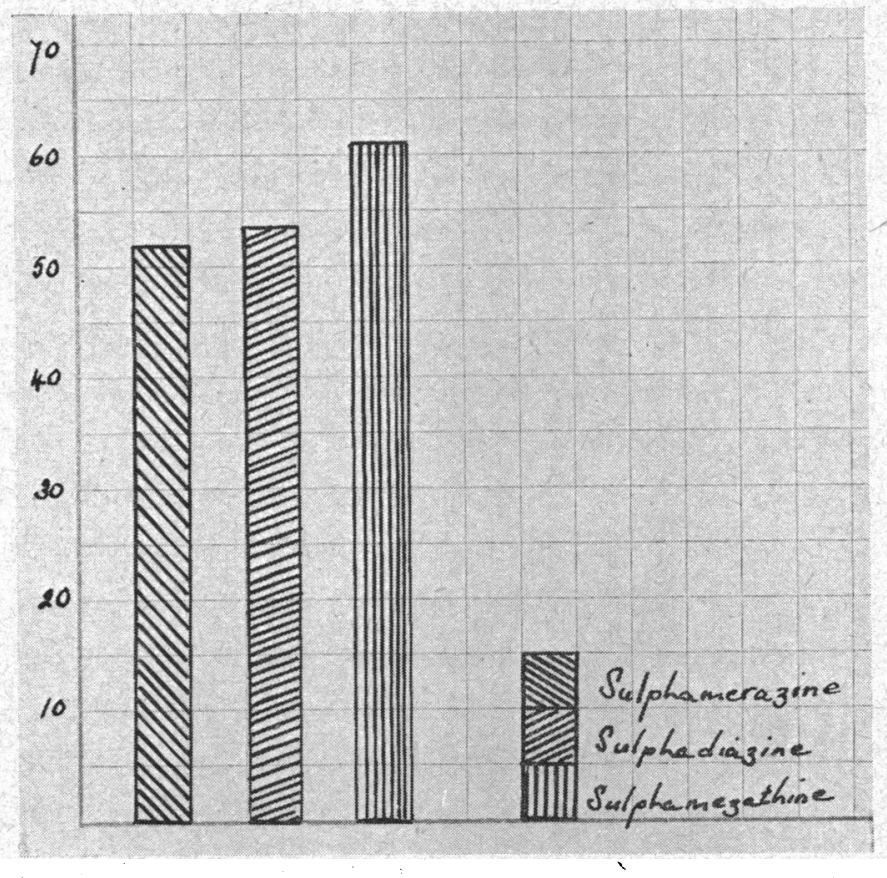

FIG. D. - Sulphonamides $-100 \mathrm{mg} . / \mathrm{kg}$. intravenously in rabbits.

Highest aqueous concentration as percentage of highest plasma concentration for each of the three sulphonamides. 


\section{Discussion}

With the reservation that whilst neither absolute values, nor ratios of aqueous concentration to plasma concentration, nor the time factors established in the experimental animal can be applied uncritically to man, the following conclusions are warranted.

(1) Absolute values in the aqueous. Sulphathiazole is the least satisfactory. In the rat both sulphanilamide and sulphamerazine give higher values than sulphadiazine and sulphamezathine, but in the rabbit both sulphadiazine and sulphamezathine give higher levels than sulphamerazine.

(2) Ratio of aqueous concentration to plasma concentration. Here, too, sulphathiazole is least satisfactory. In the rat both sulphanilamide and sulphamerazine give higher ratios than sulphadiazine and sulphamerazine, but in the rabbit there is no substantial difference between sulphamerazine and sulphadiazine, whilst sulphamezathine gives a higher value than either.

(3) Rate of excretion from anterior chamber. In the rat at 7 hours after oral administration the aqueous concentration is nil with sulphathiazole, and $4.8 \mathrm{mg} . / 100 \mathrm{ml}$. with sulphamerazine. Intermediate and successively diminishing values are recorded with sulphamezathine, sulphanilamide and sulphadiazine. In the rabbit the values at 3 hours after intravenous administration are highest for sulphadiazine, lowest for sulphamezathine and intermediate for sulphamerazine.

Eliminating sulphanilamide from consideration because of its toxicity, the one clear conclusion that emerges is the unsuitability of sulphathiazole for use in intra-ocular infections. Of the remaining three sulphonamides, sulphamezathine appears to be rather better than sulphadiazine, whilst sulphamerazine is clearly superior to sulphamezathine judging by the levels and persistence obtained in the rat-a superiority not apparent in the rabbit.

\section{SumMary}

1. Sulphonamide concentrations in the aqueous were determined for sulphanilamide, sulphadiazine, sulphamerazine, sulphamezathine and sulphathiazole after oral administration of 150 mgm. per $\mathrm{kg}$. bodyweight in the rat. Similar determinations were carried out for sulphadiazine, sulphamerazine and sulphamezathine administered to the rabbit intravenously in doses of $100 \mathrm{mg}$. per $\mathrm{kg}$. of bodyweight. Corresponding values were established for blood and plasma.

2 . In the rat the highest concentration in the aqueous was given by sulphanilamide, with successively lower readings for 
sulphamerazine, sulphamezathine, sulphadiazine and sulphathiazole. As for persistence, as measured by the presence of sulphonamide in the aqueous 7 hours after administration, sulphamerazine gave the highest value with successively decreasing values for sulphamezathine, sulphanilamide, sulphadiazine and sulphathiazole. Assessment of the highest aqueous level as a percentage of the highest plasma level showed the highest value for sulphanilamide, with successively lower values for sulphamerazine, sulphadiazine, sulphamezathine and sulphathiazole.

3 . In the rabbit the highest concentration in the aqueous was given by sulphadiazine, with successively lower values for sulphamezathine and sulphamerazine. Sulphadiazine also proved to be the most persistent as assessed by the aqueous concentration at 3 hours. The highest aqueous/plasma ratio was shown by sulphamezathine.

I am greatly indebted to Dr. A. Spinks, of the Research Laboratories. Imperial Chemical Industries Ltd., Manchester, for assistance in carrying out the experiments.

\section{REFERENCES}

Bellows and ChinN (1939).-J. Amer. Med. Assoc., 112, 2023.

(1941).-Arch. of Ophthal., 25, 294.

LIEBMAN and NEWMAN (1941).-Arch. of Ophthal., 26, 472.

MEYER, BLOCH and CHAMBERLAIN (1941).-Amer. J. Ophthal., 24, 60.

PINKOFF (1939). -Ophthalmologica, 97, 357.

SCHEIE and SOUDERS (1941).-Arch. of Ophthal., 25, 1025.

\section{THE SIGNIFICANCE OF OCULAR COMPLICATIONS FOLLOWING VACCINATION*}

BY

\section{EMANUEL ROSEN}

NEWARK, N.J.

THE occurrence of ocular complications shortly after vaccination, of the secondary or indirect variety, is not new, for it has been reported in ophthalmic literature about twelve times. The observation of a greater number of cases in a period of two months would indicate that these complications should provoke greater interest than they have hitherto received. This secondary type of ocular complication is so named in order to differentiate the accidental vaccinial inoculation produced by first scratching the

\footnotetext{
* Received.for publication, August 14, 1948.
} 